\title{
Use of Hydroxyapatite from Egg-shell as Raw Material for Synthesis Bone Graft
}

\section{SARI EDI CAHYANINGRUM ${ }^{1 *}$, NUNIEK HERDYASTUTI', BELLA DEVINA ${ }^{1}$ and MEITA KURNIASARI ${ }^{1}$}

\author{
Department of Chemistry, Faculty of Mathematics and Natural Science, \\ Universitas Negeri Surabaya, 60231, Indonesia. \\ *Corresponding author E-mail: saricahyaningrum @ unesa.ac.id
}

http://dx.doi.org/10.13005/ojc/350334

(Received: October 21, 2018; Accepted: May 10, 2019)

\begin{abstract}
In this research hydroxyapatite was synthezed from eggshell. The hydroxyapaptite was combined with Collagen and Chitosan for produce composite hydroxyapaptite/Coll/Chi by ex-situ methods. The composite HA/Coll/Chi was characterized such as a functional group and phase crystallinity and surface morphology. HA synthesized from the precursor calcium derived from eggshell reacted with $\mathrm{H}_{3} \mathrm{PO}_{4}, \mathrm{HA}$ sintered at $900^{\circ} \mathrm{C}$. Result from spectra Infra red analysis showed that there are functional group $\mathrm{PO}_{4}{ }^{3-}$ and $\mathrm{OH}$ - that characteristic for $\mathrm{HA}$. The bonding of $\mathrm{HA}$ with chitosan and collagen was showed from as well as a shift wave number in the group $\mathrm{C}=\mathrm{O}$ and $\mathrm{NH}_{2}$. Results of $\mathrm{XRD}$ analysis showed that compositon of chitosan has effect in crystalinity of bone graft.
\end{abstract}

Keywords: Hydroxyapaptite, Eggshell, Bone graft, Ex-situ.

\section{INTRODUCTION}

Bone as part of human body has very important function, so that in the event of fracture bone will cause the problem of serious health and needed technique healing for correct bone. One of the techniques for healing of bone is use synthetic bone graft biomaterial. The good synthetic of bone graft have to biocompatible, bioactive, nontoxic, supporting the nature of and osteoconductive of osteoinductive $^{1-2}$, beside that the bone graft to have composition and structure which is equal with bone, that is containing $>69 \%$ calcium phosphate, especially hidroxsiapatite; $21 \%$ collagen; $9 \%$ water and $1 \%$ other component ${ }^{3}$. Hidroxyapatite as especial component have the power of unfavorable mechanic, brittle and breakable, so that in synthesis of synthetic bone graft, the hydroxyapatite has to be composite with other material. Composite of polymer matrix have some advantage among others avoid the problem of shielding stress and eliminate second surgery procedure to eliminate implant. Mineral phase especially function of hydroxyapatite give inertia and delaying, while organic matrix give interest strength and bone flexibility ${ }^{8}$. Collagen measure up to good biocompatibility to degradation and permeated by body. In composite material, collagen and hidroxyapatite play role which is same

This is an Open Access article licensed under a Creative Commons license: Attribution 4.0 International (CC- BY). Published by Oriental Scientific Publishing Company @ 2018

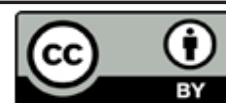


as at natural bone ${ }^{4}$. The collagen can isolated from various sources of that are ox bonde, goat, scrawl and fishbone. At this research the collagen got from scrawl. Characteristics osteoconductive and osteointegrated of graft bone relate to porosity storey level and porosity size. To form pore at graft bone need materials that added which is function as porogen. Porogen that use must have characteristic biocompatible, biodegradable and nontoxic, one of them is chitosan.

Chitosan is one of the natural polymers that is produce from chitin by deacetilazing processes. Chitosan has potency for filler in composite making. Chitosan can function as porogen. It's has characteristic non toxic, biocompatible and can improve osteoconductive bone ${ }^{5-7}$. In this research the bone graft was made by composite three materials that is hydroxyapatite/collagen of chitosan with mass composition variation of which look like with composition a period of bone. The syntheses there of bone graft are two methods able to be used are ex-situ and in-situ ${ }^{8}$. Method of ex-situ represent method addition of polymer when collagen, chitosan after especial materials in the form of hydroxyapatite have been formed, while at method of in-situ addition collagen and chitosan done at the time of process of synthesis hidroxyapatite take place. Some research indicates that method of ex situ yield product having compared to higher purity than other method.

\section{EXPERIMENTAL}

The calcium oxide was isolated from eggshell (Gallus gallus), the collagen was synthesis from scrawl (Gallus gallus) obtained from Mojosari, Indonesia. Chitosan (85\% DD), Acetic acid, nitrate acid, natrium hydroxide p.a quality purchase from Merck, Hydroxyapaptite standart (HAp-Std) from Bank Jaringan Dr. Soetomo Hospital, Surabaya, Indonesia.

\section{Synthesis of hydroxyapatite}

Synthesis hydroxyapatite was done by reacting calcium precursor and precursor phosphate with comparison of concentration of $\mathrm{Ca} / \mathrm{P} 1.67$. $\mathrm{CaO}$ powder was added by aqudemineral to yield hydroxide calcium. After that it was added with phosphate and stirrer until homogeneous and then the solution added with natrium hydroxide until $\mathrm{pH}$ 10. Mixture was aging at room temperature during
24 hours. The solution yielded to filter and its sediment is washed with aquademineral, dried at oven in temperature $110^{\circ} \mathrm{C}$ during $2 \mathrm{~h}$ after that, it was added with nitrate acid and sintering in $900^{\circ} \mathrm{C}$ during 2 hours. The crystal that produces was cooled in furnace and produce hydroxyapatite.

\section{Synthesis of hydroxyapatite- collagen- chitosan bone graft}

Amount of chitosan was dissolved in acetate acid solution. It solution was stirred until homogeneous. Hydroxyapatite powder have been dissolved with water was added in chitosan solution with wish drop method. After that it solution was added with collagen solution. The composite that produce was treatment with freeze dry and then condensed on natrium hydroxide solution. After that the composite was dried in freeze dry again. The processed repeat again for composite with variation Massa composition HA/Coll/Chi 7:1.5:1.5 and 7:1:2. Composite HA/Coll/Chi was characterized functional group and crystalinity.

\section{RESULTS AND DISCUSSION}

At hidroxyapatite synthesis from an eggshell which must be calcinazed to change $\mathrm{CaCO}_{3}$ became $\mathrm{CaO}$. CaO powder was soluted in aquademineral form $\mathrm{Ca}(\mathrm{OH})_{2}$, solution. It solution was added with phosphoric acid solution drop to drop so that $\mathrm{pH}$ not go down drastically. The rate of phosphoric acid addition very related to obtained $\mathrm{pH}$ in the end of synthesis. Degradation at $\mathrm{pH}$ under 7 causing imperfect dissociation of phosphoric acid so that yield $\beta-\mathrm{Ca}_{3}\left(\mathrm{PO}_{4}\right)_{2}$ and $\mathrm{CaO}$. Phosphoric acid solution that was added with slowly can increase the homogeneity of solution ${ }^{9,10}$. At the research, the synthesis of hydroxyapatite is undergone at temperature $60^{\circ} \mathrm{C}$, this function is to crystal maximalized produce and reduces produce monoclinic crystal structure. The monoclinic crystal structure can produce in temperature under at $60^{\circ} \mathrm{C}^{11}$. Hydroxyapatite that synthesis is expected has structure same with bone structure, there are hexagonal structure. When phosphoric acid was added in calcium hydroxide solution the solution slowly condensation become to have the character of acid, while process of crystallization take place effective at base condition ${ }^{12}$ that the solution must be added with natrium hydroxide until $\mathrm{pH} 10$, hydroxyapaptite crystal stabile at $\mathrm{pH} 10^{13}$ 
The hydroxyapatite from synthesis with variation sintering temperature compared with hydroxyapatite standard from Bank Jaringan. Fig. 2 showed the spectra of $\mathrm{CaO}$, hydroxyapatite that sintering at 800 (Hydroxyapaptite-800); hydroxyapatite-900; hydroxyapaptite $-1000^{\circ} \mathrm{C}$; hydroxyapatite without sintering and hydroxyapatite standart from Bank Jaringan (HAp-std).

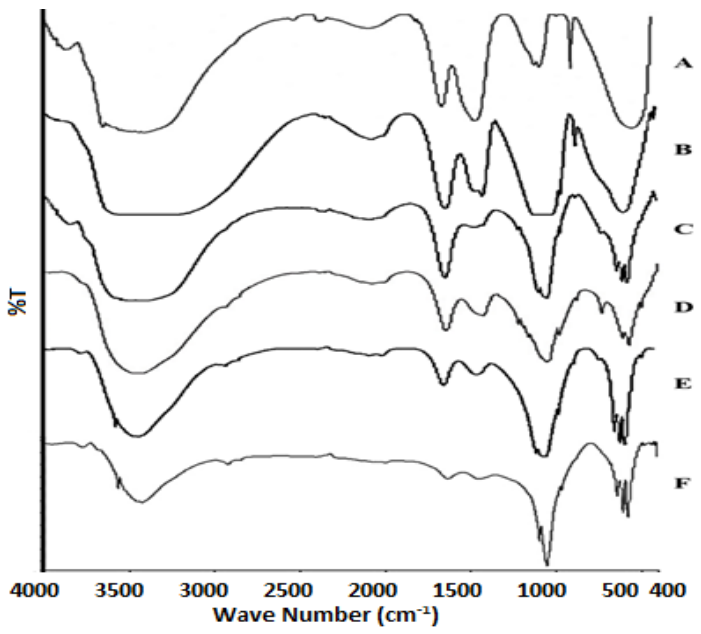

Fig. 1. FTIR spectra of (A) $\mathrm{CaO}$, (B) Hydroxyapaptit-Non sintering, (C) Hydroxyapatite-800, (D) Hydroxyapatite-900,

(E) Hydroxyapatite-1000, (F) and Hydroxyapatite-std

Sample HAp-TS has characteristic spectra at wave number $411.07 ; 1095 ; 576.97 ; 1400.36$; 659.96; and $1648.76 \mathrm{~cm}^{-1}$. At Fig. 2B spectra don't band at 630 $\mathrm{cm}^{-1}$ because these phase HAp has more impurities than HAp that was undergo sintering processes. The characteristic of HAp-800 are have peak at 963.26; 495.2; 1070.5; 570; 602.5; 1420.21; 631.27; 1637.49; and $3401.04 \mathrm{~cm}^{-1}$. Spectra Fig.1D. has band at around 454.76; 1072.5; 528.5; and $163801 \mathrm{~cm}^{-1}$. The characteristic spectra for Fig.1E there are have spectra at around 403.26; 1074.5; 575.5; 1638.01 and $3435,21 \mathrm{~cm}^{-1}$. The wave number for spectra samples $\mathrm{A}-\mathrm{F}$ are similar there is characteristic for $\mathrm{CO}_{3}{ }^{2-}, \mathrm{PO}_{4}{ }^{3-}$, and $\mathrm{OH}$ - functional groups.
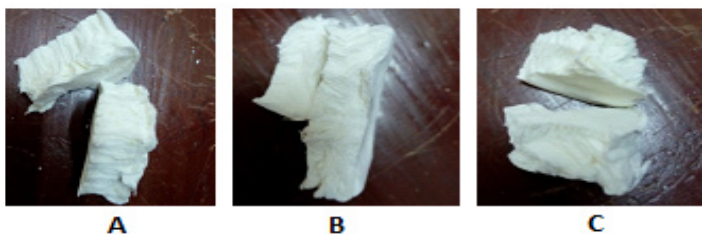

Fig. 2. Bone graft 7:2:1 (A); 7:1.5:1.5 (B) and 7:1:2 (C)

At Fig. 2 seen that all bone graft have physical character of solid with white in colour.
All bone graft has hollow fiber which result bone graft do not too hard when depressed. Pursuant to perception of physical seen bone graft have been mingled is homogeneously. Bone graft $A$ with content of chitosan at most brass white in color, more and more content of chitosan hence its color tend to turn white brass. Bone graft $\mathrm{C}$ also more solid and resilient when compared with bone graft $B$ and bone graft A. Progressively the increasing of chitosan the bone graft seen it more resilient.

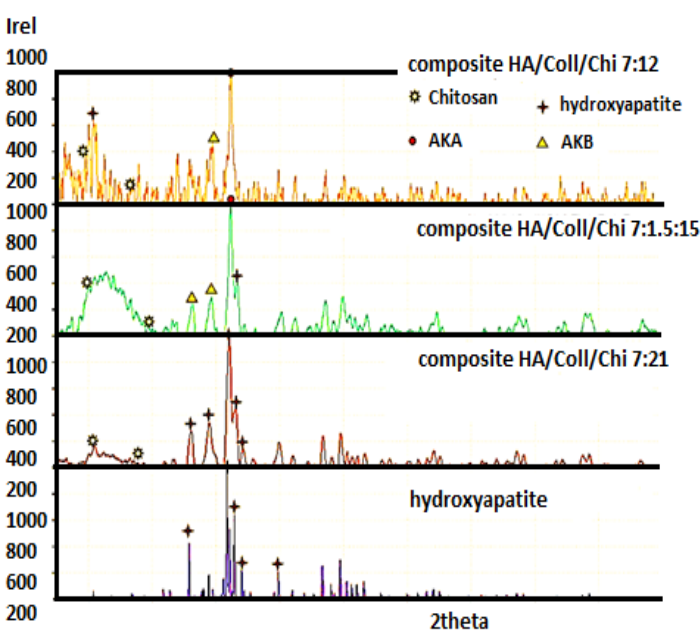

Fig. 3. Difractogram of hydroxyapatite; bone graft $7: 1: 2$; 7:1.5:1.5 and 7:2:1

At Fig. 3 saw the difractogram of hydroxyapaptie was dominant hydroxyapatite phase, with highest difractograme at $31.76^{\circ}$ and $31.8^{\circ}$. This phase there are in three bone graft. Beside phase hydroxyapatite in this research produse another phase there are apatite carbonat type $A$ and apatite carbonat type $\mathrm{B}$. The highest intensity of difractogram is $100 \%$ for bone graft $\mathrm{HA} / \mathrm{Coll} / \mathrm{Chi} 7: 2: 1$ with $2 \theta$ eangle is $=32.14^{\circ}$ and $32.08^{\circ}$. The bone graft $\mathrm{HA} /$ Coll/Chi 7:1.5:1.5 and HA/Coll/Chi 7:1:2, the phase dominant is apatite carbonat type A with $2 \theta=32.32^{\circ}$ and $32.4^{\circ}$. The Hydroxyapatite phase on bone graft $\mathrm{HA} / \mathrm{Coll} / \mathrm{Chi}$ 7:1.5:1.5 is relatife medium there at $85.57 \%$ and $2 \theta=32.18^{\circ}$, while on bone graft $\mathrm{HA} / \mathrm{Coll} / \mathrm{Chi}$ 7:1:2 phase of hydroxyapaptite at $2 \theta$ $=32.18^{\circ}$.

At Fig. 4 showed that organic material has effect in crystalinity, addition of collagen influence degree of crystalinity. Graft Bone with amount of at most of collagen, the crystalinity is lowest. Collagen is organic material with amorf character. 


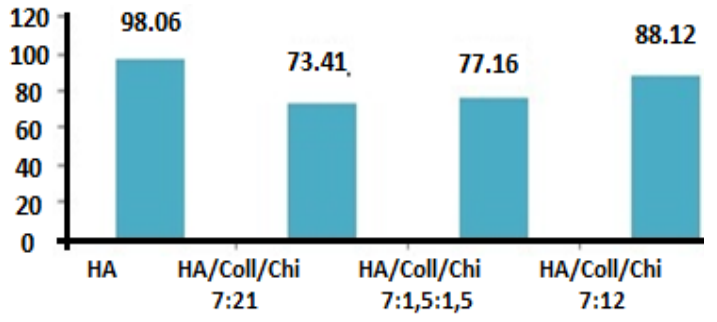

Fig. 4. Crystalinity degree of HA; bone graft 7:2:1; 7:1.5:1.5 and $7: 1: 2$

\section{CONCLUSION}

Hydroxyapatite that produce from eggshell with precipitation wet method have functional group similar with hydrxyapatite standard from Bank Jaringan, there are characteristic for $\mathrm{CO}_{3}{ }^{2-}, \mathrm{PO}_{4}{ }^{3-}$, and $\mathrm{OH}$ - functional groups. The hydroxyapatite was composed with collagen and chitosan to produce bone graft $\mathrm{Ha} / \mathrm{Coll} / \mathrm{Chi}$. Graft Bone with amount of at most of collagen, the crystalinity is lowest.

\section{ACKNOWLEDGMENT}

We would like to thank to DRPM DIKTI which has provided financial support through National Priority Research Programme, Hibah Penelitian Berbasis Kompetensi Programme 2018 with No. Contract: 000001.92/UN38.11-P/LT/2018, February 12, 2018.

\section{REFERENCES}

1. Jamarun,N; Azharman,Z; Arief, S; Sari, T.P; Asril, A; and Elfina, S; Rasayan Journal of Chemistry., 2015, 8, 133-137.

2. Oshida; Yoshiki; Wang, Sun, C; Qu and Liang, K; Hydroxyapapite Synthesis and Apllication. New York: Momentum Press., 2015.

3. Cahyaningrum, S.E; Herdyatuty, N; Supangat,D; Devina, B; and Kurniasari, M. Rasayan Journal of Chemistry., 2018, 11, 488-493.

4. Pallela, R; Sreedhar, B; and Janapala, VR.1 Int J Biol Macromol., 2011, 49, 85-92.

5. Halabalova, $\mathrm{V}$; Simek, L; and Mokrejs, $\mathrm{P}$ Rasayan Journal of Chemistry., 2011, 4, 223-241

6. Huang, Z; Feng,Q; Yu,B; and Li S.Materials Science and Engineering C., 2011, 31 683-687.

7. Puntharoda, R; Sankrama, C; Chantarameec,N; Pookmaneea,P; and Haller, K.J. Journal of Ceramic Processing Research., 2013, 14, 198- 201.
8. Wattanutchariya, W and W. Changkowcha, W. 2014. Proceedings of the International MultiConference of Engineers and Computer Scientists. IMECS, Hong Kong ., 2014, 2, $12-14$.

9. Gou,Q; Reza,G; Thomas,W; Andreas, A; Evgeny,L; Cemal, E; Olaf, M;Wei,C; Boris,C; and Andreas; O., Polymers., 2014, 6, 2037-2055.

10. Tangboriboon, N; Khongnakhon,T; Kittikul,S; Kunanuruksapong, R and Sirivat,A. J. Sol-Gel Sci. Technol., 2011, 58, 33-41.

11. Anita.L.J;, Ravichandran, Kand Sundareswari, M. Journal of Chemical and Pharmaceutical Research., 2015, 7, 231-239.

12. Malina, D;Biernat, $\mathrm{K}$ and Kupiec, A.S. Acta Bichimica Polonica., 2010, 60, 851-855.

13. S.V Dorozhkin, Bioceramics of Calcium Orthophosphates. Biomaterials., 2010, 31, 1465-85 